\title{
Evaluation of sand-clay-anionic polyacrylamide blends for alternative compacted clay landfill liner design
}

\author{
Mauro Codevilla ${ }^{1,2}$, Camilo Casagrande ${ }^{1,2}$, Marcos Montoro ${ }^{4,5}$, Sandra Orlandi ${ }^{6}$, Teresa Piqué.$^{1}$ and Diego Manzanal ${ }^{2,3^{*}}$ \\ ${ }^{1}$ Facultad de Ingeniería, Universidad de Buenos Aires (UBA), Argentina. \\ ${ }^{2}$ Inst. de Tecnología y Ciencias de la Ingeniería INTECIN-UBA-CONICET, Argentina. \\ ${ }^{3}$ ETSCCyP, Universidad Politécnica de Madrid (UPM), España \\ ${ }^{4}$ Facultad de Ciencias Exactas, Físicas y Naturales - Universidad Nacional de Córdoba, Argentina \\ ${ }^{5}$ Instituto de Estudios Avanzados en Ingeniería y Tecnología (IDIT CONICET - FCEFyN UNC), Argentina \\ ${ }^{6}$ Universidad Nacional de la Patagonia San Juan Bosco, Argentina.
}

\begin{abstract}
In this project, an innovative low hydraulic conductivity material for landfill cover and liner construction was studied. The material is a blend of natural clayey soil from Comodoro Rivadavia city (Chubut province, Argentina) mixed with fine uniform sand and anionic polyacrylamide (APAM). The research emphasizes understanding the influence of APAM addition on the soil water retention capacity (SWRC), unsaturated hydraulic conductivity, and swelling behavior. APAM is a super absorbent polymer that swells when immersed in water. SWRC was evaluated through the filter paper method. The unsaturated hydraulic conductivity and swelling behavior were determined using two fluids: distilled water and brine (C $=2 \mathrm{M})$. Results showed that APAM addition reduced the blends' microporosity, increased the water retention capacity, and reduced the hydraulic conductivity of the system. These promising results encourage further research on these blends' behavior to determine the most efficient blend formulation to enhance its hydromechanical performance and its chemical compatibility with landfill leachates for cover and low hydraulic conductivity liner layer construction.
\end{abstract}

\section{Introduction}

Engineered landfills are facilities of uttermost importance for integrated solid waste management systems all over the world. The performance of these facilities relies on the efficiency of their low hydraulic conductivity liner and cover systems. These systems are composed of a combination of layers with different specific functions. One of the most critical layers is the low hydraulic conductivity barrier. These barriers use to be constructed either by compacted fine soils, compacted blends of soils and expansive clays, industrial by-products such as fly ash, polymers, or by geosynthetics products such as geomembranes and geosynthetic clay liners. This research aims to analyze the behavior of sand-clay-polymer blends for low hydraulic conductivity cover or liner layer construction for municipal solid waste landfills.

\subsection{Particle - polymer - fluid interaction}

Design and construction characteristics and requirements of cover and liner layers for contaminant containment are usually specified in many local and international standards and regulations. These layers' primary purpose is to isolate waste and contaminants from the external environment, preventing liquid, solid, or gas migration or infiltration from the dumping cells. Both systems can be constructed using different materials such as local compacted and stabilized fine soils, geosynthetic products, or a combination of these two materials (Giroud and Bonaparte 1989 [1]). Table 1 shows technical requirements for the cover and liner system and the main technical problems associated with each one.

Most natural local soils do not fit the indicated requirements for liner and cover construction also after compaction. Therefore, they must usually be stabilized with the addition of other materials.

Sand - clay blends are usually considered for liners construction (Abichou et al. 2002 [2]; Al Rawas 2006 [3]; Stern et al. 1998 [4]). Sands are employed as support materials, while clays are included due to their volume change properties, which help to reduce hydraulic conductivity when they swell due to hydration (Kolstad et al. 2004 [5]; Scalia and Benson 2011 [6]).

For sand - clay liners design and construction, it is important to determine the proportions of sand and clay required to obtain a blend that has appropriate compaction properties and also proper mechanic and hydraulic properties (Daniel et al. 1990 [7]; Stern et al. 1998 [4]). Optimum clay content depends on clay mineralogy. There is no general agreement about the minimum clay content required in the blends to reach target hydraulic conductivity values specified in the regulations. For

\footnotetext{
*Corresponding author: diego.manzanal@gmail.com, mcodevilla@fi.uba.ar
} 
highly plastic clays such as montmorillonite, some authors recommend a clay content between 5 to $15 \%$ (Geddouda et al. 2008 [8]), while for the case of kaolinite clays, researchers recommend clay content over $20 \%$ (Al Rawas et al. 2006 [3]). There are reports of previous studies performed on local materials in Argentina that indicates clay contents between $12-15 \%$ in order to fulfill technical requirements (Montoro and Francisca 2010 [9]; Pique et al. 2019 [10]).

Table 1. Basic requirements and problems for cover and liner systems.

\begin{tabular}{|c|c|c|c|}
\hline \multicolumn{2}{|c|}{ Final Cover system } & \multicolumn{2}{|c|}{ Liner system } \\
\hline Requirements & Problem & $\begin{array}{c}\text { Requiremen } \\
\text { ts }\end{array}$ & Problem \\
\hline $\begin{array}{c}\mathrm{k}<10^{-7} \mathrm{~m} / \mathrm{sec} \\
\text { - Resistance to } \\
\text { superficial } \\
\text { erosion } \\
\text { - Flexibility } \\
\text { - Rapid surface } \\
\text { water runoff } \\
\text { - Barrier } \\
\text { between waste } \\
\text { and vegetation } \\
\text { - Gas } \\
\text { recollection } \\
\text { - Odor control }\end{array}$ & $\begin{array}{l}\text { - Roots } \\
\text { penetration } \\
\text { - Freezing- } \\
\text { thawing } \\
\text { action } \\
\text { - Traffic } \\
\text {-Differential } \\
\text { settlement }\end{array}$ & $\begin{array}{l}\mathrm{k}<10^{-9} \mathrm{~m} / \mathrm{sec} \\
\text { - Strength } \\
\text { - Flexibility }\end{array}$ & $\begin{array}{l}- \\
\text { Leachate } \\
\text { percola- } \\
\text { tion } \\
\text { - Shorten- } \\
\text { ing } \\
\text { duration } \\
\text { of barrier }\end{array}$ \\
\hline
\end{tabular}

Clay particles present net electric unbalanced charges in their faces and edges that allow the formation of an electrical field surrounding each particle. Because of that electric field, cations are attracted to particle's faces giving a non-uniform ion concentration in each particle's surroundings. The region affected by the clay electrical charges' presence is known as the electric diffuse double layer (EDL).

The EDL thickness depends on bulk fluid ion concentration, ion valence, dielectric permittivity constant of the pore fluid, and the system temperature. Hükel - Debye length equation 1 gives EDL thickness (Mitchell and Soga 2005 [11]).

$$
\vartheta=\sqrt{\frac{\epsilon_{0} K^{\prime} k T}{2 n_{0} e^{2} v^{2}}}
$$

where $e=1.60210^{-19} \mathrm{C}$ is the electron charge, $\epsilon_{0}$ is the permittivity of free space, $K^{\prime}$ is the real relative permittivity of the fluid, $v_{i}$ is the ion valence, $n_{i o}$ is the ionic concentration, $k=1.3810^{-23} \mathrm{~J} / K$ is Boltzmann's constant, and $T$ is the temperature.

EDL formation is responsible for particle-fluid interaction mechanisms that affect swelling properties, hydraulic conductivity, and contaminant transport and retardation (Bowders and Daniel 1987 [12]; Santamarina et al. 2001 [13]).

Polymers can also be included in blends in order to improve their performance. Typical polymers included are ionic polyacrylamide (Barvenik 1994 [14]). Net electrical charges presented in the polyacrylamide allows interacting with soil particles affecting blends macroscopic properties such as swelling characteristics, hydraulic conductivity, shear strength, compressibility, soil water retention curves, and contaminant retardation and sequestration (Mamedov et al., 2007 [15]; Scalia and Benson 2016 [6]; Zhou and Gao 1993 [16]).

Polymer addition to soils has previously been investigated for other engineering applications such as soil erosion control (Orts et al. 1999 [17]; Yang et al. 2011 [18]), swelling control (Orlandi et al. [32,33]), and soil water retention capacity (Fernandez et al. [34]).

Several authors studied clay - polymer blends. Since the early '40s, the research effort was applied to understand better polymer - soil - fluid interaction (Michaels 1954 [19]; Theng 1974 [20]). Traditionally polymer molecules are adsorbed directly onto clay particle's surfaces. This adsorption phenomenon modifies EDL thickness and, consequently, the properties of the blends (Theng 1979 [21]). This process occurs in the case of cationic or non - ionic polymers. However, because anionic polymers have negative charges, they interact with clay particles' surfaces through hydrogen bonds or cationic "bridges." APAM adsorption will only be possible by the presence of cations (Mortensen 1962 [22]). Although several authors accepted this mechanism, further research is needed to clarify all physic-chemical mechanisms involved in polymer - clay interaction (Laird 1997 [23]). Figure 1 clarifies these mechanisms.

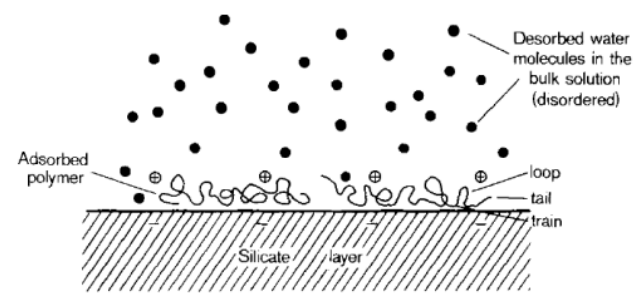

Fig. 1. Clay - polymer interaction (Theng, 1979 [21]).

Volume change properties of compacted blends are also important to guarantee the integrity of liner and covers when subjected to differential settlements or when subjected to wetting and drying cycles (Inyang and Bae 2005 [24]).

Changes in osmotic suction can explain swelling height and swelling pressure of blends after hydration according to van't Hoff equation (2) (van't Hoff 1884 [25]):

$$
\pi=R T \sum c_{i}^{\text {interp }}-c_{i}^{\text {bulk }}
$$

were $c_{i}^{\text {interp }}$ is the molar concentration on interparticle space, $c_{i}^{\text {bulk }}$ is the molar concentration of bulk permeant fluid, $R$ is the gas constant $\left(8.321 \mathrm{kPa} / \mathrm{mol}^{\circ} \mathrm{K}\right)$, and $T$ is the absolute temperature of the system.

\section{Materials}

\subsection{Sand and clay}


In this research, we used two different natural soil types for preparing soil blends to test their feasibility to be used as material for compacted clay liner or cover construction. We used Parana river's sand as supporting material or coarse fraction, which is natural sand composed of uniform clean rounded silica particles.

As fine soil addition, we used natural clay obtained from open pits at Comodoro Rivadavia city (Chubut, Argentina) $\left(45^{\circ} 49^{\prime} 36.35^{\prime \prime S}-67^{\circ} 27^{\prime} 47.68^{\prime \prime} \mathrm{W}\right)$. The fine soil is a grey clayey soil that was initially deposited in a marine environment. It is highly overconsolidated and expansive clay (Orlandi et al., 2015 [26], Manzanal et al 2019 [35]). Table 2 summarizes the physical properties of clay and river sand studied in this research.

Table 2. Physical properties of clay and sand.

\begin{tabular}{c|c|c|l}
\hline Property & Sand & Clay & ASTM \\
\hline USCS & SP & MH & D2487 \\
\hline LL [\%] & - & 60 & D4318 \\
\hline IP [\%] & - & 21 & D4318 \\
\hline$\# 200[\%]$ & 5 & 95 & D1140 \\
\hline Clay F. [\%] & - & 24 & D422 \\
\hline $\mathrm{Cu}_{\mathrm{u}}, \mathrm{C}_{\mathrm{c}}[-]$ & $2.5,1.3$ & - & D422 \\
\hline $\mathrm{D}_{50}[\mathrm{~mm}]$ & 0.38 & - & D422 \\
\hline $\mathrm{S}_{\mathrm{s}}\left[\mathrm{m}^{2} / \mathrm{gr}\right]$ & 2 & 220 & $\begin{array}{l}\text { (Santamarina } \\
\text { et al. 2002 } \\
[27])\end{array}$ \\
\hline $\mathrm{Gs}_{\mathrm{s}}[-]$ & 2.67 & 2.70 & ASTM D854 \\
\hline
\end{tabular}

\subsection{Anionic polyacrylamide (APAM)}

Polyacrylamide (PAM) is a non-ionic super-absorbent polymer composed of a large chain of monomers obtained from the polymerization of acrylamide (Barvenik 1994 [14]). They have an important capacity for water absorption and retention, and they can act as a hydrogel (Mechtcherine 2015 [28]). In the presence of ionic elements, PAM will release absorbed water due to interference with hydrogen bonding.

Commercial anionic PAMs (APAM) are manufactured in different ways. Figure 4 refers to the production of APAM from the hydrolysis of non-ionic PAM with a strong base of $\mathrm{NaOH}$.
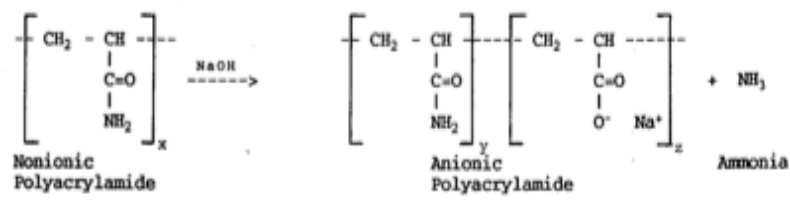

Fig. 2. Hydrolysis of non-ionic PAM (Barvenik, 1994 [14]).

APAM has net negative electrical charge density that ranges between 2 to $40 \mathrm{~mol} \%$ for many commercial APAMs (Barvenik 1994 [14]; Michaels 1954 [19]) has suggested that non-ionic polymer do not have a good interaction with soil particles. On the other hand, an
APAM with a high anionic charge has a long chain due to the repulsion of negatively charged groups, which enhance APAM - soil's particles interaction through hydrogen bonds or cation bridges. Table 3 summarizes the most relevant physical properties of APAM.

Table 3. Physical properties of APAM (data provided by the manufacturer)

\begin{tabular}{c|c}
\hline Property & APAM \\
\hline Molecular weight $[\mathrm{Mg} / \mathrm{mol}]$ & $10-20$ \\
\hline Density $\gamma\left[\mathrm{kN} / \mathrm{m}^{3}\right]$ & 7.85 \\
\hline $\mathrm{D}_{50}[\mathrm{~mm}]$ & 0.30 \\
\hline Glass temperature transition $\left.\mathrm{Tg}_{\mathrm{g}}{ }^{\circ} \mathrm{C}\right]$ & 84 \\
\hline Anionic charge density $[\mathrm{mol} \%]$ & $>30$ \\
\hline Absorption $[\%]$ & 60 \\
\hline
\end{tabular}

\subsection{Fluids}

Two different fluids were used to understand the importance of particle - polymer - fluid interaction: distilled water $\left(\sigma_{\mathrm{el}}=10^{-6} \mathrm{~S} / \mathrm{m}, \mathrm{K}^{\prime}=80\right)$ and brine $\left(\sigma_{\mathrm{el}}=12\right.$ $\left.\mathrm{S} / \mathrm{m}, \mathrm{K}^{\prime}=55, \mathrm{C}=2 \mathrm{M}\right)$.

All compacted blends were prepared using distilled water before testing. Then, swelling tests and hydraulic conductivity tests were performed using either distilled water or brine according to the testing program. At the same time, Soil Water Characteristic Curves were determined only using distilled water.

\section{Methods}

\subsection{Sand-clay-polymer blends preparation}

In previous research performed at the geotechnical research laboratory of the Universidad de Buenos Aires, Marti et al. 2015 [29] studied compaction properties of blends having different sand, clay, and APAM content in order to determine the blend that allows having the highest dry unit weight after compaction and the associated optimum moisture content. In that regard, the authors found that blends composed of $85 \%$ - sand $15 \%$ clay presented the maximum dry unit weight after compaction. In this research, clay-APAM blends were prepared, considering $85 \%$ of sand as a coarse fraction and $15 \%$ of fine fraction. The fine fraction was prepared as clay mixed with either $1.5,2.5$, and $3.5 \%$ of APAM by dry weight (i.e., $100 \mathrm{gr}$ of a blend of $85 \%$ sand- $15 \%$ (clay $+1.5 \%$ APAM) represents $85 \mathrm{gr}$ sand, $14.77 \mathrm{gr}$ of clay, and $0.23 \mathrm{gr}$ of APAM).

All samples were prepared by static compaction at $95 \%$ of maximum dry unit weight and optimum moisture content. Mixtures were stored in a humid chamber for at least 12 hours before testing to allow uniform particle and polymer hydration. Figure 3 shows an example of sandclay-APAM where narrow threads of the hydrated polymer can be observed. 


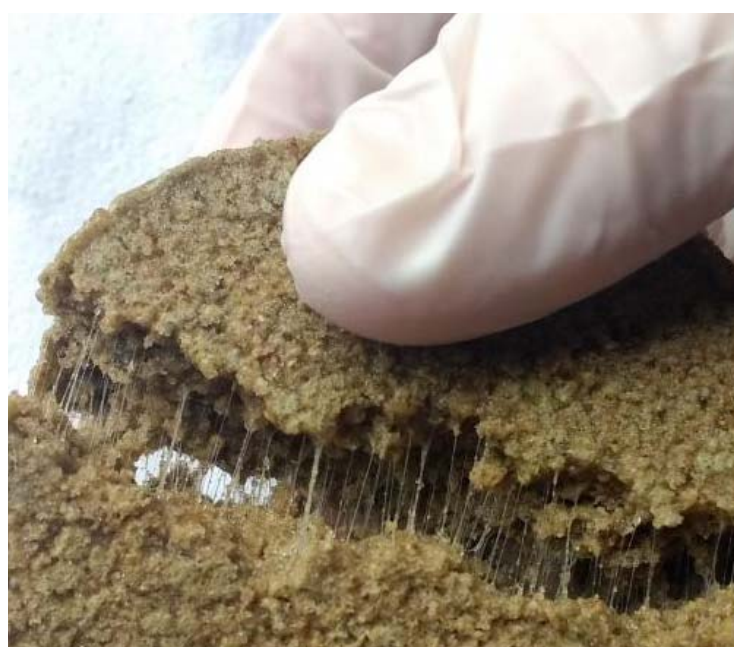

Fig. 3. Macroscopic view on sand-clay-APAM mixture.

\subsection{Testing program}

Table 4 shows the testing program proposed in order to understand the sand-clay-APAM interaction. Tests included free swelling test, soil water retention curve (SWRC), and unsaturated hydraulic conductivity. Distilled water and brine $\mathrm{C}=2 \mathrm{M}$ were used as permeant fluids except on SWRC tests.

\begin{tabular}{|c|c|c|}
\hline Test & Mixtures & Fluid \\
\hline $\begin{array}{c}\text { Free } \\
\text { Swelling }\end{array}$ & $\begin{array}{c}85 \% \text { sand- } \\
15 \% \text { (clay }+0,1.5, \\
2.5,3.5 \% \text { APAM) }\end{array}$ & $\begin{array}{c}\text { D. Water } \\
\text { Brine } C=2 M\end{array}$ \\
\hline $\begin{array}{l}\text { Soil Water } \\
\text { Retention } \\
\text { Curve }\end{array}$ & $\begin{array}{c}85 \% \text { sand- } \\
15 \% \text { (clay }+0,1.5, \\
2.5,3.5 \% \text { APAM) }\end{array}$ & D. Water \\
\hline $\begin{array}{l}\text { Unsaturated } \\
\text { Hydraulic } \\
\text { Conductivity }\end{array}$ & $\begin{array}{c}85 \% \text { sand- } \\
15 \%(\text { clay }+0 \\
3.5 \% \text { APAM })\end{array}$ & $\begin{array}{c}\text { D. Water } \\
\text { Brine } C=2 \mathrm{M}\end{array}$ \\
\hline
\end{tabular}

Free swelling tests were performed following the general guidelines indicated in ASTM D 4546 under an initial applied normal pressure between 5 to $10 \mathrm{kPa}$. SWRC tests were performed using the filter paper method following the general guidelines specified in ASTM D 5298. The filter paper was a calibrated Schleicher \& Schuell 589/2 (Bicalho 2007 [30]). More than seven days were necessary to reach a hygrothermal equilibrium.

Unsaturated hydraulic conductivity tests were performed using small soil columns samples $(h=104 \mathrm{~mm}$, $\phi=101 \mathrm{~mm})$. Groups of samples with similar APAM content were prepared for measuring the saturation profile after fluid infiltration. The saturation profile was measured at fixed times. This method allowed calculating $\mathrm{k}_{\text {unsat }}$ using Darcy's law equation (3) :

$$
k_{w \text { unsat }}=\frac{\Delta w G_{s}(\Delta x)^{2}}{(1+e) \Delta t\left(\Delta z+\frac{\Delta u_{w}}{\gamma_{w}}\right)}
$$

were $\Delta w=$ change in gravimetric moisture content, $G_{s}=$ specific gravity, $\Delta x=$ vertical distance on soil column height, $e=$ initial void ratio, $\Delta t=$ time interval, $\Delta z=$ change on potential energy head, $\Delta u_{w}=$ change on pore water pressure, $\gamma_{w}=$ unit weight of water. Figure 4 shows the basic configuration of the infiltration test.

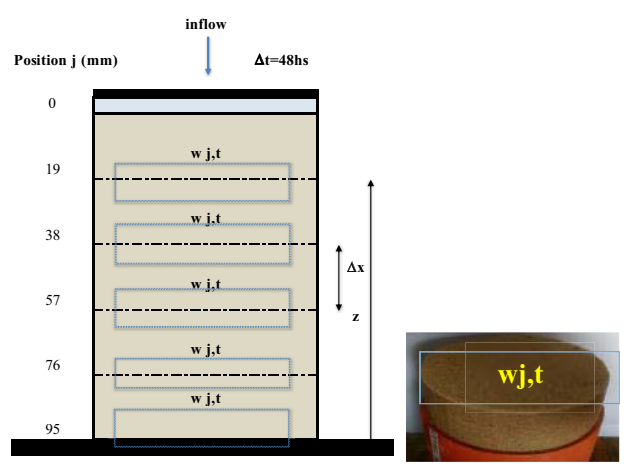

Fig. 4. Soil infiltration column (left). Sample extruded for measure moisture content $\left(\mathrm{w}_{\mathrm{j}, \mathrm{t}}\right)$ at $z$ position on time $\Delta t$ (right).

For performing the measurements, five different specimens of $85 \%$ sand $-15 \%$ (clay $+0 \%$ APAM) and four different specimens of $85 \%$ sand-(15\%clay $+3.5 \%$ APAM $)$ were tested using distilled water as permeating fluid, while for tests conducted using brine $\mathrm{C}=2 \mathrm{M} 3$ different specimens of $85 \%$ sand $-15 \%$ (clay $+0 \%$ APAM) and 2 different specimens of $85 \%$ sand-(15\%clay+3.5\%APAM) were tested. Time spans between measurements depend on the hydraulic conductivity of each specimen and for each testing fluid. In that regard, time span ranged between several days (1 to 14 days) for tests performed using distilled water to several hours or minutes $(8 \mathrm{~min}$ to $24 \mathrm{hs}$ ) for the case of tests performed using brine $\mathrm{C}=2 \mathrm{M}$.

\section{Results}

\subsection{Free swelling}

Figure 5 and Table 5 show the results obtained from free swelling tests. Only the specimens permeated with distilled water showed an increment of height with the increment in APAM content. Specimens of $85 \%$ sand$15 \%$ (clay +1.5 or $3.5 \%$ APAM) tested with brine $\mathrm{C}=$ $2 \mathrm{M}$ showed a small reduction of height. Besides, $85 \%$ sand- $15 \%$ (clay $+0 \%$ APAM) sample tested with distilled water showed no height change during the test.

\subsection{Soil water retention curves}

Figure 6 and Table 6 show results on SWRC tests. The experimental data was fitted using van Genuchten's equation (4)

$$
S_{r}=\left[1+\left(\frac{u_{a}-u_{w}}{s_{a e}}\right)^{\frac{1}{1-\lambda}}\right]^{-\lambda} \cdot\left(1-S_{r e s}\right)+S_{r e s}
$$

were $s_{a e}=$ air entry value, $\lambda=$ pore size distribution index and $S_{\text {res }}=$ residual degree of saturation. In fact, those fitting parameters are used by Brooks \& Corey equation (Brooks \& Corey 1966) but it is usually accepted to write equation 4 in this way because van Genuchten's original fitting parameters $(a, n, m)$ have no explicit physical meaning (Fredlund, et al. 2012 ). 
There is some controversy when considering the residual saturation degree as a physical parameter (Luckner et al., [36]) or a calibration parameter (e.g. Fredlund \& Xing [38], Manzanal et al., [39, 40]). In this work, we used the second approach. Test results show an increment of air entry pressure value and residual degree of saturation at higher APAM content. On the other hand, a slight reduction of $\lambda$ parameter is observed with the increase of APAM content.

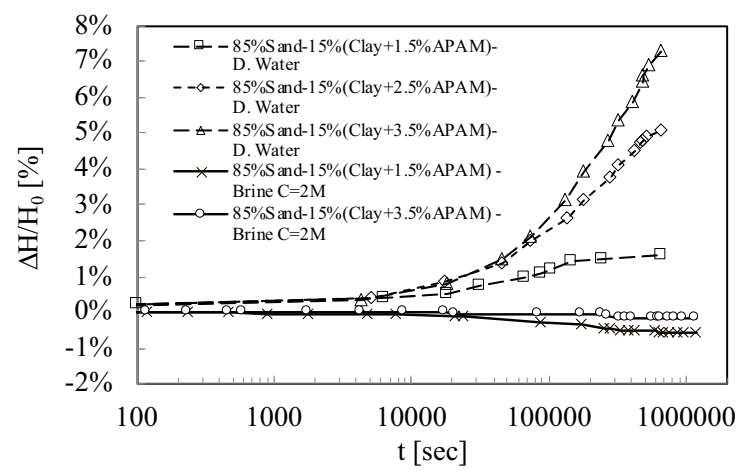

Fig. 5. Free swelling test results (permeant fluids: distilled water and brine $\mathrm{C}=2 \mathrm{M}$ ).

Table 5. Initial state samples and free swelling test results.

\begin{tabular}{c|c|c|c}
\hline Mixture & $\begin{array}{c}\gamma_{\mathrm{d} 0} \\
(\mathbf{k N} / \mathbf{m} \\
\mathbf{3}\end{array}$ & $\begin{array}{c}\mathbf{S}_{\mathbf{r} 0} \\
\mathbf{( \% )}\end{array}$ & $\begin{array}{c}\Delta \mathbf{H} / \mathbf{H} \\
\mathbf{0} \\
(-)\end{array}$ \\
\hline permeant fluid: distilled water \\
\hline $85 \%$ sand-15\%(clay + 0.0\%APAM) & 16.97 & 63.4 & $<0.1$ \\
\hline $85 \%$ sand-15\%(clay + 1.5\%APAM) & 16.04 & 56.4 & 1.58 \\
\hline $85 \%$ sand-15\%(clay + 2.5\%APAM) & 15.93 & 57.4 & 5.05 \\
\hline $85 \%$ sand-15\%(clay + 3.5\%APAM) & 16.95 & 57.3 & 7.26 \\
\hline permeant fluid: brine C=2M \\
\hline $85 \%$ sand-15\%(clay + 1.5\%APAM) & 16.59 & 58.7 & -0.59 \\
\hline $85 \%$ sand-15\%(clay + 3.5\%APAM) & 16.34 & 56.4 & -0.18 \\
\hline
\end{tabular}

Table 6. Basic parameters for van Genuchten equation on soil water retention curves.

\begin{tabular}{c|c|c|c}
\hline Mixture & $\begin{array}{c}\text { Sae } \\
(\mathbf{k P a})\end{array}$ & $\begin{array}{c}\mathbf{S}_{\text {res }} \\
\mathbf{( \% )}\end{array}$ & $\begin{array}{c}\boldsymbol{\lambda} \\
(-)\end{array}$ \\
\hline $85 \%$ sand-15\%(clay + 0\%APAM) & 3.0 & 20 & 0.68 \\
\hline $85 \%$ sand-15\%(clay + 1.5\%APAM) & 5.5 & 25 & 0.65 \\
\hline $85 \%$ sand-15\%(clay + 2.5\%APAM) & 6.5 & 29 & 0.60 \\
\hline $85 \%$ sand-15\%(clay + 3.5\%APAM) & 6.0 & 28 & 0.60 \\
\hline
\end{tabular}

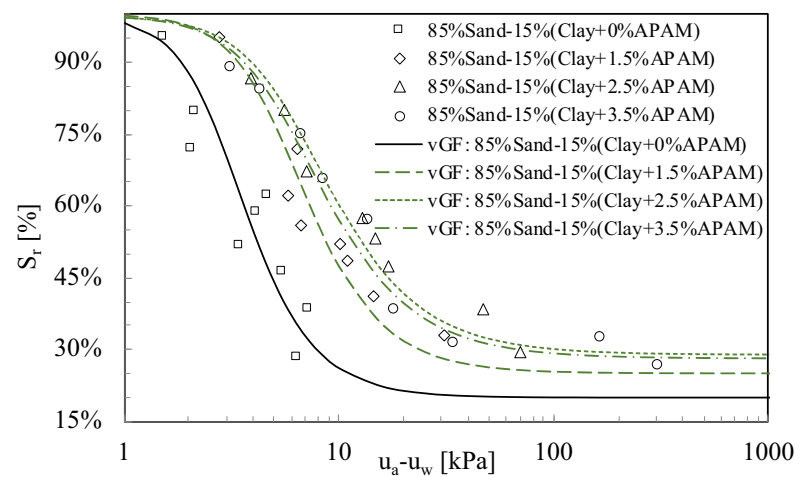

Fig. 6. Soil water retention curves according to van Genuchten equation (vGF).

\subsection{Unsaturated hydraulic conductivity}

Figures 7 and Figure 8 show the unsaturated hydraulic conductivity varying with matric suction for different permeant fluids on sand-clay and sand-clay-APAM blends. Values of unsaturated hydraulic conductivity were obtained by equation (3). The matric suction evolution was obtained from SWRCs controlling the moisture content at different times. Tests on specimens permeated with distilled water reached full saturation after 14 days, while specimens permeated with brine required less than 4 days to reach full saturation.

Samples with $3.5 \%$ of APAM permeated with distilled water presented a reduction in the unsaturated hydraulic conductivity of one order of magnitude (from $\mathrm{k}_{\mathrm{W}}$ unsat $=10^{-8}$ to $10^{-9} \mathrm{~m} / \mathrm{s}$ ). In addition to that, samples having $3.5 \%$ of APAM presented a reduction of two orders of magnitude in the unsaturated hydraulic conductivity (from $\mathrm{k}_{\mathrm{w}}$ unsat $=10^{-6}$ to $10^{-8} \mathrm{~m} / \mathrm{s}$ ) when permeated with brine.

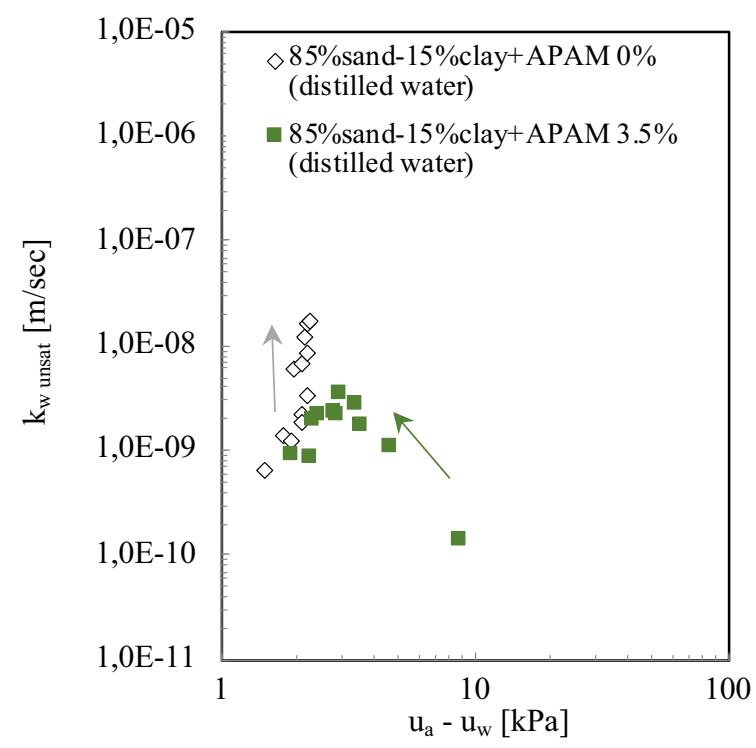

Fig. 7. Unsaturated hydraulic conductivity test for $85 \%$ sand$15 \%$ clay $+0,3.5 \%$ APAM mixtures vs matric suction (permeant fluid: distilled water). 


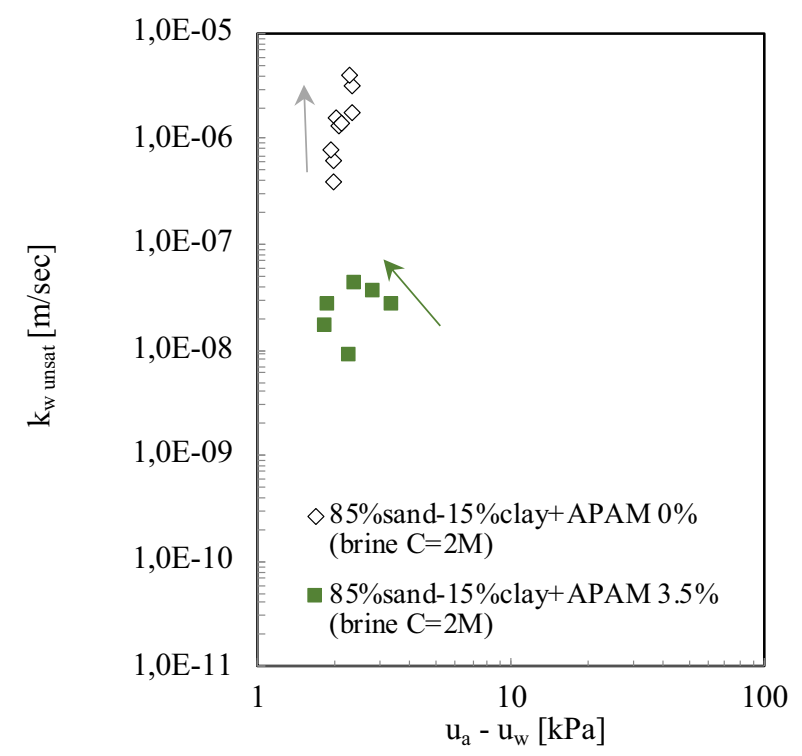

Fig. 8. Unsaturated hydraulic conductivity test for $85 \%$ sand$15 \%$ clay $+0,3.5 \%$ APAM mixtures vs matric suction (permeant fluid: brine $\mathrm{C}=2 \mathrm{M})$.

\section{Discussion}

\subsection{Changes on Free swelling by APAM addition}

Figure 9 shows the variation of free swelling versus APAM content. Dotted lines represent the general tendency of change in specimen height after swelling with APAM content change for the different fluids. The general trend shows that samples' height increases with the increase in APAM content when tests are performed using distilled water while presenting almost no change or a contraction when tests were performed using brine.

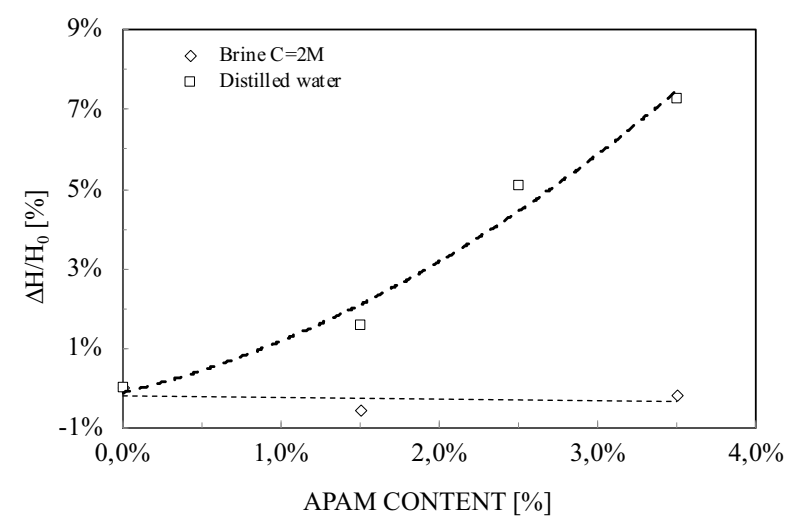

Fig. 9. Variation of specimen height after swelling for $85 \%$ sand$15 \%$ clay $+\%$ APAM mixtures for different fluids (distilled water and brine $\mathrm{C}=2 \mathrm{M}$ ).

Changes in swelling heights can be explained by analyzing changes in osmotic pressure given by equation 2. The addition of APAM to the blends tends to increase the ionic concentration on the interparticle space $\left(\uparrow c_{i}^{\text {interp }}\right.$ ) due to the high electrical surface charge density of the APAM and the increase in cation concentration between clay particles and APAM chains. Because of changes in osmotic pressure, the increase in ionic concentration increases electric repulsion or swelling pressure. In that regard for higher APAM contents, it is expected higher initial height changes.

On the other hand, for the case of changing the permeating fluid from distilled water by brine, this change leads to an increase in bulk fluid ionic concentration $\left(\uparrow c_{i}^{b u l k}\right)$. Hence, low swelling and osmotic pressure are expected, and in consequence, less changes in initial sample heights are also expected. Similar tendencies were previously reported by Benson and Scalia 2014 [31].

\subsection{Changes on SWRC by APAM addition}

Figure 10 shows the main changes in SWRC for specimens having different APAM content. There is a significant change on, $s_{a e}, \lambda$ and $S_{r e s}$ of the SWRC for $1.5 \%$ of APAM while for APAM contents above $1.5 \%$ there are no significant changes SWRC parameters.

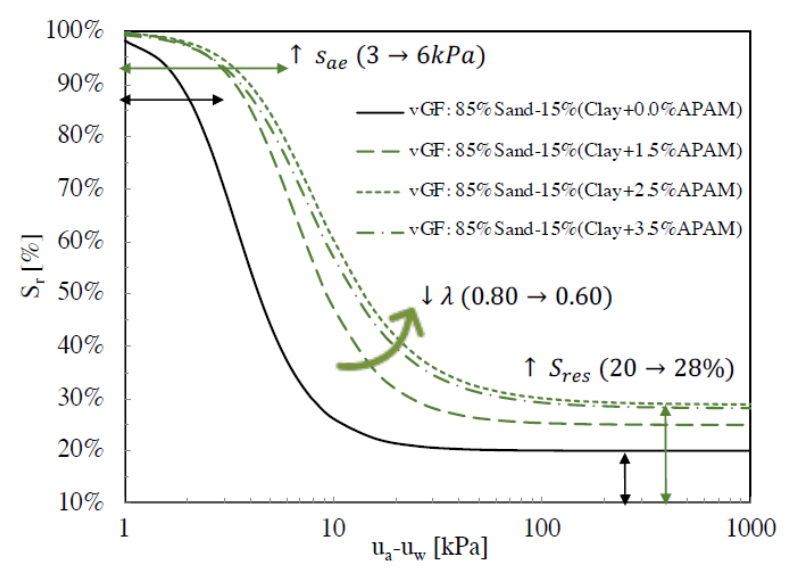

Fig. 10. van Genuchten curves for $85 \%$ sand $-15 \%$ clay+APAM mixtures.

Assuming that the addition of APAM in the sandclay mixture does not modify water surface tension or the contact angle; the increment in $S_{a e}$ and $S_{r e s}$ is observed because the increase in APAM content affects the original pore sizes in the blend leading to smaller pores [10]. Also, the increase in APAM content is reflected in the reduction in the pore size distribution index $(\lambda)$, meaning that pores of smaller sizes are present in the samples.

For each suction value, there is a representative pore radius given by equation (5)

$$
s_{a e}=\frac{h_{c}}{\gamma_{w}}=2 \sigma_{a v} \cos \theta \frac{1}{r_{p}}
$$

Where $h_{c}$ is the capillary rise, $\gamma_{w}$ the unit weight of water, $\sigma_{a v}$ the air-void surficial tension, $\theta$ the contact angle and $r_{p}$ the pore radius. The hypothesis of the reduction in pore size due to APAM addition is consistent with the high values on free swelling tests showed in Figure 5, and less value on unsaturated hydraulic conductivity tests showed in Figures 7 and Figure 8. The typical general behavior observed for fine soil applies alos in this case: changes in pore size distribution affects hydro-mechanical behavior. 


\subsection{Changes on unsaturated conductivity by APAM addition}

hydraulic

It is expected an increase in hydraulic conductivity with a decrease in matric suction. Figures 7 and 8 show the hydraulic conductivity versus matric suction for samples with and without APAM for the two permeant fluids.

The samples' initial degree saturation is between 57.3 to 63.7 since samples were prepared at near the optimum moisture content. For that initial value of degree of saturation, the change of suction along the imbibition paths of the SWRC lies in a very narrow range. For samples with APAM addition, there is a little increase in suction since $\lambda$ parameter is lower than samples without APAM.

Specimens with no APAM addition and tested with distilled water showed $\mathrm{k}_{\mathrm{w}}$ unsat values starting at $10^{-8}$ and finishing close to $10^{-9} \mathrm{~m} / \mathrm{s}$. Samples tested with distilled water having APAM addition showed less value of hydraulic conductivities than the previous one.

Tests performed with brine showed an increase in hydraulic conductivity. This trend is no significant for samples with APAM due to EDLs development and APAM - particle interaction, which affects free pore space available for fluid flow and increases flow paths tortuosity.

\section{Conclusions}

In this research, we explored the behavior of sand - clay - APAM blends for their application in cover and liner layers' construction for landfills. The main conclusions obtained can be summarized as follows:

- The increase in APAM content on blends up to $1.5 \%$ affects their behavior.

- Volume change properties changes are more important with the increase in APAM content. Swelling increases with the increase of APAM content when tests were performed with distilled water. On the other hand, low or null swelling behavior was observed for brine tests, highlighting the importance of fluid chemical properties on the particle - fluid - APAM interaction.

- APAM addition affects the initial pore fabric of samples. The increase in APAM content represents a decrease in pore sizes and a broader pore size distribution reflected in the change of SWRC shapes, the increase in air pressure entry value, and the pore size distribution index.

- Values obtained in unsaturated hydraulic conductivity are in the range of the required by most regulations for landfill cover and liner construction. Observed trends in hydraulic conductivity changes with matric suction change highlight that behavior must be explained considering simultaneously unsaturated soil behavior and particle - fluid interaction.

\section{References}

1. J.P. Giroud \& R. Bonaparte (1989). Leakage through liners constructed with geomembranes, part II: composite liners. Geotextiles and Geomembranes. 8, 71-111.

2. T. Abichou, C. Benson, \& T. Edil (2002). Microstructure and hydraulic conductivity of simulated sand-bentonite mixtures. Clays, and Clay Minerals, 50(5), 537-545.

3. A. Al-Rawas, Y. Mohamedzein, A. Al-Shabibi \& S. Al-Katheiri (2006). Sand-Attapulgite Clay Mixtures as a Landfill Liner. Geotechnical and Geological Engineering. 24: 1365-1383.

4. R. Stern \& C. Shackelford (1998). Permeation of sand-processed clay mixtures with calcium chloride solutions. J. of Geotechnical and Geoenvironmental Engineering. 124:3, 231-241. https://doi.org/10.1061/(ASCE)10900241(1998)124:3(231).

5. D. Kolstad, C. Benson, T. Edil (2004). Hydraulic conductivity and swell of nonprehydrated GCLs permeated with multi-species inorganic solutions. J. Geotech. Geoenviron. Eng. 130:12, 1236-1249. doi: 10.1061/(ASCE)1090-0241 (2004)130:12(1236).

6. J. Scalia \& C. Benson (2011). Hydraulic conductivity of geosynthetic clay liners exhumed from landfill final covers with composite barriers. J. Geotech. Geoenviron. Eng. 1943, 1-13. doi: 10.1061/(ASCE)GT.1943-5606.0000407.

7. D. Daniel \& C. Benson (1990). Water contentdensity criteria for compacted soil liners. Journal of Geotechnical Engineering, Vol. 116, No. 12, pp 1811-1830.

8. M.K. Gueddouda, M. Lamara, N. Aboubaker, S. Taibi (2008). Hydraulic conductivity and shear strength of dune sand-bentonite mixtures. Electron Journal Geotechnical Engineering 13:1-15.

9. M. Montoro \& F. Francisca (2010). Soil Permeability Controlled by Particle-Fluid Interaction. Geotech Geol. Eng., doi:10.1007/s10706-010-9348-y

10. M. Piqué, D. Manzanal, M. Codevilla y S. Orlandi (2019). Polymer Enhanced Soils Mixture for Potential Use as Covers or Liners in Landfill Systems Environmental Geotechnics. Published Online: August 23, 2019, doi: 10.1680/jenge.18.00174.

11. J. K. Mitchell \& K. Soga (2005). Fundamentals of soil behaviour. Wiley, Hoboken, NJ.

12. J. J. Bowders \& D. E. Daniel (1987). Hydraulic conductivity of compacted clay to dilute organic chemicals. J. Geotech. Eng., doi: 10.1061/(ASCE)0733-9410(1987)113:12(1432), 1432-1448.

13. J. C. Santamarina, K. A. Klein \& M. A. Fam (2001). Soils and waves. Wiley, New York.

14. F.W. Barvenik (1994). Polyacrylamide characteristics related to soil applications. Soil Science. 58:235-243.

15. A. Mamedov, S. Beckmann, C. Huang, G. Levy (2007). Aggregate stability as affected by 
polyacrylamide molecular weight, soil exture, and water quality. Soil Science Society of America Journal $\quad \mathbf{7 1}(6)$ :1909-1918, https://doi.org/10.2136/sssaj2007.0096.

16. Z. Zhou \& D. Gao (1993). Polymer-Modified Clay as Impermeable Barriers for Acid Mining Tailings. MEND/NEDEM Report 6.2, Canada. http://mendnedem.org/mend-report/polymer-modified- clay-asimpermeable-barriers-for-acid-mining-tailings/.

17. W.J. Orts, R.E. Sojka, G.M. Glenna, R.A. Gross (1999). Preventing soil erosion with polymer additives. Polymer News 24(1): 406-413.

18. L-x Yang, S-c Li, H-I Sun et al. (2011). Polyacrylamide molecular formulation effects on erosion control of disturbed soil on steep rocky slopes. Canadian Journal of Soil Science 91(6): 917924, https://doi. org/10.1139/CJSS10087.

19. A.S. Michaels (1954). Aggregation of suspensions by polyelectrolytes. Industrial Engineering Chemistry 46 : 1485-1490.

20. B. K. Theng (1974). The Chemistry of Clay-Organic Reactions : Adm Hilger, London, 343 pp.

21. B. K. Theng, (1979). Formation and Properties of Clay-Polymer Complexes. Elsevier, Amsterdam, pp 362.

22. J.L. Mortensen, (1962). Adsorption of hydrolysed polyacrylonitrile on kaolinite: in Clays and Clay Minerals, Proc. $9^{\text {th }}$ Natl. Conf. West Lafayette, Indiana, 1960, Ada Swineford, Ed. Pergamon Press, New York, 530-545.

23. D.A. Laird (1997). Bonding between polyacrylamide and clay mineral surfaces. Soil Science 162:826-832.

24. H.I. Inyang \& S. Bae (2005). Polyacrylamide sorption opportunity on interlayer and external pore surfaces of contaminant barrier clays. Chemosphere $\mathbf{5 8}(1)$, 19-31, 10.1016/j.chemosphere.2004.08.090

25. Van 't Hoff (1884). Études de Dynamique Chimique. Frederik Muller, Amsterdam.

26. S. Orlandi, D. Manzanal, A. Ruiz, M. Avila, M. Graf, (2015). A case study on expansive clays on Comodoro Rivadavia city. From Fundamentals to Applications in Geotechnics, D. Manzanal \& A.O. Sfriso (Eds.) IOS Press, 2015. pp: 2276-2283. doi: 10.3233/978-1-61499-603-3-2276.

27. J. C. Santamarina, K. Klein, Y. Wang, E. Prencke (2002). Specific surface: determination and relevance. Can. Geotech. J. 39: 233-241. Technical note.

28. V. Mechtcherine, E. Secrieru \& C. Schröfl (2015). Effect of super-absorbent polymers (SAPs) on rheological properties of fresh cement-based mortars - Development of yield stress and plastic viscosity over time. Cement and Concrete Research, vol. 67, p. 52.

29. L. Marti, M. Codevilla, T. Piqué, D. Manzanal (2015). Natural soil modified with polymer for use in landfill systems. From Fundamentals to Applications in Geotechnics. D. Manzanal \& A.O. Sfriso (Eds.) IOS Press, 2015. pp: 2228-2235. doi: 10.3233/978-161499-603-3-2228.

30. K. Bicalho, A. Correia, S. Ferreira, J. M. Fleureau, F. a. M. Marinho (2007). Filter paper method of soil suction measurement. Advances in Unsaturated Soils, 225-230.

31. J. Scalia, C. Benson, G. Bohnhoff, T. Edil, C. Shackelford (2014). Long-term hydraulic conductivity of a bentonite-polymer composite permeated with aggressive inorganic solutions. J. Geotech. Geoenviron. Eng., doi: 10.1061/(ASCE)GT.1943-5606.0001040, 04013025.

32. S. Orlandi, D. Manzanal, E. Miranda, M. Robison, (2019) Using lignin as stabiliser of swelling soils. XVI Pan-American Conference on Soil Mechanics and Geotechnical Engineering 17-20 November 2019. Cancun, México. doi: 10.3233/STAL190295.

33. S. Orlandi, M.E. Taverna, Y. Villada, T. Piqué, C. Laskowski, V. Nicolau, D. Estenoz, D. Manzanal (2020). Additives based on vegetable biomass to improve the stabilization of expansive clay Soil. Environmental Geotechnics. Accepted.

34. M. Fernandez, S. Orlandi, M. Codevilla, T. Piqué, D. Manzanal (2020) Permormance of Calcium Lignosulfonate as stabilizer of highly expansive clay. Transportation Geotechnics, 27 (2021) 100469. https://doi.org/10.1016/j.trgeo.2020.100469.

35. D. Manzanal, S. Orlandi, J.C. Barria (2019). Swell characterisation of expansive clays from Comodoro Rivadavia - Argentine. XVI Pan-American Conference on Soil Mechanics and Geotechnical Engineering. 17-20 November 2019. Cancun, Mexico. doi:10.3233/STAL190107.

36. L. Luckner, M. T. Van Genuchten, D. R. Nielsen ( 1989), A consistent set of parametric models for the two-phase flow of immiscible fluids in the subsurface, Water Resour. Res., 25(10), 2187-2193, doi:10.1029/WR025i010p02187.

37. D.G. Fredlund \& A. Xing (1994). Equations for the Soil-Water Characteristic Curve. Canadian Geotechnical Journal, 31, 521-532.

38. D. Manzanal, M. Pastor, M. Fernandez, M. Merodo (2011). Generalized plasticity state parameter-based model for saturated and unsaturated soils Part II: unsaturated soil modeling. Int. J. Numer. Anal. Met. 35 (18), 1899-1917. doi: 10.1002/nag.983

39. D. Manzanal, M. Pastor, M. Fernandez, M. Merodo, P. Mira (2010). A state parameter based Generalized Plasticity model for unsaturated soils. Computer Modelling in Engineering and Science CMES, 55, no.3, pp.293-317, $2010 . \quad$ doi: 10.3970/cmes.2010.055.293 